\title{
Friction stir processing of austenitic stainless steel cold spray coating deposited on 304L stainless steel substrate: feasibility study
}

\section{Thomas Perard}

University of Lyon, National Engineering School of Saint-Etienne

Alexey Sova ( $\square$ sova.aleksey@gmail.com )

University of Lyon, National Engineering School of Saint-Etienne

Hugo Robe

Institut de Soudure, Zone d'Activit_es A_eroport de Metz

Vincent Robin

EDF, Le Recamier, 70 rue Robert

\section{Yasser Zedan}

Mechanical Engineering Department, Ecole de technologie suprieure (ETS)

\section{Philippe Bocher}

Mechanical Engineering Department, Ecole de technologie suprieure (ETS)

Eric Feulvarch

Mechanical Engineering Department, Ecole de technologie suprieure (ETS)

\section{Original Research}

Keywords: Friction Stir Processing, Cold Spray, Stainless steel, Microstructure

Posted Date: February 3rd, 2021

DOl: https://doi.org/10.21203/rs.3.rs-190685/v1

License: (9) This work is licensed under a Creative Commons Attribution 4.0 International License. Read Full License 


\section{Abstract}

In this work the feasibility test of friction stir processing (FSP) of $1.5 \mathrm{~mm}$ thick austenitic stainless steel cold spray coating deposited on 304L stainless steel substrate was performed using tungsten carbide tool. Applied FSP parameters (advance speed $50 \mathrm{~mm} / \mathrm{min}$, rotation speed $300 \mathrm{rpm}$, axial force $20 \mathrm{kN}$, tilt angle $1.5^{\circ}$ ) allowed to perform FSP treatment with a higher depth than the coating thickness. As a result, the material mixing at the coating/substrate interface was observed. The microstructure observation revealed that the coating microstructure in the stir zone was significantly modified. EBSD analysis confirmed that full material recrystallization during FSP allowed to formation of dense and uniform finegrain structure with the mean grain size $1.9 \mathrm{~mm}$. Average coating microhardness was decreased from $406 \mathrm{HV}$ to $299 \mathrm{HV}$. Further FSP parameters optimization should be carried out in order to improve the process reliability and avoid any coating failure during treatment.

\section{Introduction}

Austenitic stainless steels are widely used for different industrial applications thanks to their excellent corrosion resistance in various aggressive environments and high mechanical properties at elevated temperatures. For example, 304L and 316 L stainless steels are used for production of pressure tubes in thermal and nuclear power plants and connection pipes and other parts in chemical factories. However, after some service time, some component damage may occur due to wear, fatigue, or other causes. Damaged stainless steel components could be replaced or repaired, depending on the nature of failure, the component dimensions and complexity.

Nowadays, different material deposition techniques involving high temperature processes like welding, laser cladding etc. are widely used for stainless steel component repair [1-3]. The main advantages of these methods are high quality of the interface between the part and deposited material, high process robustness and acceptable cost. However, in some cases the application of these methods is difficult due to significant thermal impact. In particular, in case of repair of complex parts with the microstructure, the extensive heating of the deposition site induces high thermal stresses that could distort the repaired part.

Cold spray is the solid-state material deposition process providing an alternative to the high-temperature technologies. In this process, the supersonic jet of preheated gas formed by converging-diverging nozzle accelerates particles of metal powder. The particle adhere to the surface due to local material recrystallization of the particle induced by high-speed plastic deformation during impact. As a result, the deposit consisting of highly deformed particles forms [4-6]. Nowadays, cold spray is applied for the repair of parts produced from the heat-sensitive materials like aluminum and magnesium alloys [7]. For example, successful application of cold spray for restoration of aircraft skin was reported $[8,9]$. However, it is important to note, that the properties of cold spray deposit significantly differ from the reference values measured for the bulk material produced in traditional way. In particular, due to specific structure of the particle-particle interface, the ductility of cold spray deposits is very low $[6,10]$. In addition, the elevated porosity diminishing the tensile strength of deposit is observed in case of deposition of hard 
materials [11]. Results of successful cold spray deposition of austenitic stainless steel are available in literature [12-19]. It was found that besides high deposition efficiency, the coating could have elevated porosity in case of spraying with nitrogen $[11-13,17,18]$. Fragile behavior of the coating at tensile strength tests, typical for cold spray deposits, was also reported [15].

Previous studies showed that heat treatment or hot isostatic pressing could significantly improve the mechanical properties of cold spray deposits [15, 20-24]. In these processes, the high temperature enhance the material diffusion through the particle-particle interface and lead to formation of joint grains between neighbor particles. As a result, the mechanical properties of deposits such as ductility and toughness increase. However, in case of restoration work, these post-treatment techniques are not always applicable due to dimension restriction of restored part.

In this regard, application of friction stir processing (FSP) offers a promising alternative to the thermal post-processing methods. In FSP process, a rotating tool inserted into the material generates the frictional heating contact. During tool movement along the contact line, plastic material occurs at a temperature below the melting point as for cold spray. The plastic ow transfers the material from the advancing side to retreating side, leading to the formation of a stirred region $[25,26]$. It is considered that the formation of a fine grain structure during FSP of metals is attributed to the dynamic recrystallization phenomena combined with thermomechanical treatment $[27,28]$. Nowadays FSP is used to refine the surface microstructure of various bulk materials such as bronze [29], aluminum and magnesium [30, 31]. Application of FSP for the treatment of harder materials like steels and nickel-based alloys is complicated. In case of proper parameter selection, the FSP treatment can increase the microhardness on the austenitic stainless steels surface by formation of nanosized grains [32].

At present, many articles devoted to the friction stir processing of cold spray despots are available in literature [20,33-42]. The major part of these works deal mainly with FSP treatment of relatively soft materials like aluminum and copper alloys [33-38]. It was shown, that friction stir processing allowed to completely modify the microstructure of cold spray deposits. In particular, full material recrystallization and grain refinement was observed [33-35]. No particle-particle interface is visible in the deposits after FSP [36-38]. The improvement of tensile strength and ductility was also reported. As it was mentioned earlier, the friction stir processing of steels and other metals with high mechanical properties is difficult due to high tool load required for proper material deformation during tool rotation. However, some experiments with FSP of titanium and stainless steel cold spray coatings are also presented in the literature [39-42]. In these works, the authors successfully demonstrated the feasibility of FSP treatment of hard material deposits. Significant microstructure modification and material grain refinement was observed.

It is important to note that in all reported cases with FSP treatment of stainless steel deposits, the depth of the coating layer affected by FSP treatment did not exceed 200-300 mm [41, 42]. However, from practical point of view, in case of application of cold spray for the stainless steel part repairing, it could be necessary to perform the FSP treatment of the deposits with significantly higher thickness. The main 
purpose of this work was the feasibility study of friction stir processing of austenitic stainless steel cold spray deposits with the depth affected by the treatment equal to $1 \mathrm{~mm}$ or more. The parameter selection of FSP process and its influence on the structure and the properties of the deposit after were also considered.

\section{Process Parameters And Methodology}

\subsection{Cold Spray: materials and deposition parameters}

Commercially available austenitic stainless steel powder Diamalloy 1003 supplied by Oerlikon Metco was used for coating deposition. The SEM images of the powder is presented in Figure 1. Powder composition is provided in the Table 1.

Table 1: Chemical composition (in wt \%) of Diamalloy 1003 stainless steel feedstock powder.

\begin{tabular}{|llllll|}
\hline $\mathrm{Fe}$ & $\mathrm{Cr}$ & $\mathrm{Ni}$ & $\mathrm{Si}$ & $\mathrm{C}$ & $\mathrm{Mo}$ \\
\hline Bal. & $17 \%$ & $12 \%$ & $2.3 \%$ & $0.03 \%$ & $2.5 \%$ \\
\hline
\end{tabular}

The chemical composition of the Diamalloy 1003 powder was close to the standard composition of 316L stainless steel, except the percentage of silicon. Increased content of silicon in the powder leads to the higher oxidation and sulfidation resistance, but on the other hand decreases ductility of the alloy.

The cold sprayed coating deposition was performed with the commercially available system CGT KINETIKS 4000 equipped by the nozzle OUT-1 provided by Impact Innovation (Germany). Nitrogen was used as the working gas. The process parameters used in this study are summarized in Table 2 . In the table $P$ and $T$ denote the gas stagnation pressure and temperature respectively. $V_{s}$ is the scanning velocity of the nozzle, $d$ is the distance between two passes and $n$ is the number of layers. These parameters allowed to deposit the Diamalloy 1003 coatings with deposition efficiency about $75 \%$. The coating thickness was in the range between 1.4 and $1.5 \mathrm{~mm}$. The strategy of the nozzle displacement as well as the geometry of the final samples are presented in Figure 2. The rectangular 304L stainless steel plates were used as the substrates. The composition of the plates is presented in Table 3.

Table 2: Spraying parameters.

\begin{tabular}{|llllll|}
\hline Gas & $P$ & $T$ & $V_{s}$ & $d$ & $n$ \\
\hline Nitrogen & 35 bars & $600^{\circ} \mathrm{C}$ & $100 \mathrm{~mm} / \mathrm{s}$ & $3 \mathrm{~mm}$ & 2 \\
\hline
\end{tabular}

Table 3 Chemical composition of 304L stainless steel used as substrate

\begin{tabular}{|lllllllll|}
\hline Fe & $\mathrm{Cr}$ & $\mathrm{Ni}$ & $\mathrm{Si}$ & $\mathrm{C}$ & $\mathrm{Mn}$ & $\mathrm{P}$ & $\mathrm{S}$ & $\mathrm{N}$ \\
\hline Bal. & $18 \%$ & $6 \%$ & $0.3 \%$ & $0.03 \%$ & $1.2 \%$ & $0.045 \%$ & $0.015 \%$ & $0.11 \%$ \\
\hline
\end{tabular}


Initially, the tests with coating deposition were performed using three different surface preparation techniques: acetone cleaning (i), grit blasting (ii) and chemical machining (iii). In case of grit blasting, alumina grains with particle size Mesh 16 accelerated by air jet with stagnation pressure of 10 bars were used for surface roughening. The chemical machining was performed using ferric chloride solution. Approximately $200 \mathrm{~mm}$ of the material was chemically removed from the top surface during treatment.

Preliminary tests revealed that in case of spraying on the acetone cleaned and grit-blasted substrate, the coating immediately delaminated from the substrate surface after deposition due to weak adhesion strength and high residual stresses. However, in case of deposition on the substrate after chemical machining, the coatings without visible defects were produced (Figure 3 ).

Higher coating adhesion on the substrate prepared by chemical machining could be explained by decrease of the hardness value at the substrate surface. Chemical machining allowed to remove the material from near-surface zone affected (hardened) by rolling process and machining during substrate manufacturing. As a consequence, the spraying is performed on softer surface than in case of raw or grit blasted substrates. The results of nanohardness measurements on the substrate before and after chemical machining are presented in Figure 4. Figure 4 shows that the nanohardness in the near-surface zone of the substrate dropped from more than 4GPa for the raw plate to $3.3 \mathrm{GPa}$ for the substrate after chemical machining. The SEM images of the top surfaces of the raw substrate after acetone cleaning and chemical machining are presented in Figure 5. One can see that in contrast to the raw substrate, the grains are well visible on the surface of the plate after chemical machining. This observation confirmed that the chemical machining allowed to remove the superficial layer of the plate that leaded to adhesion improvement.

The detailed study of the coating adhesion improvement by application of chemical machining was not the purpose of this study; however, it is important to note that the deposition of the final batch of samples for further FSP treatment was done using the substrates after chemical machining.

\subsection{Friction Stir Processing: tool and processing parameters}

The FSP experiments were performed using a dedicated Friction Stir Welding gantry machine (MTSISTIR) with a tungsten carbide tool. As shown in Figure 6, the tool geometry is composed of a $15 \mathrm{~mm}$ diameter at shoulder with a $1.4 \mathrm{~mm}$ long tapered pin. The length of the pin was chosen to be sufficient for stirring all the thickness of the Diamalloy 1003 cold spray coating down to the interface with the 304L substrate. Figure 7 shows the positioning of the specimens and the clamping conditions as well as the tool during the plunging phase of the pin. Pure argon was used as shielding gas in order to prevent the high temperature oxidation of the tool and material during processing.

In case of processing of stainless steel, the proper selection of FSP parameters is complex task. Miles et al. [43] and Selvam et al. [44] considered an advancing velocity $V$ between $50 \mathrm{~mm} / \mathrm{min}$ and $150 \mathrm{~mm} / \mathrm{min}$ whereas the rotating speed $\mathrm{N}$ achieved $250 \mathrm{rpm}$ for a pin length greater than $6 \mathrm{~mm}$ in the case of processing of bulk stainless steel. Hajian et al. [45] used a tool without pin with a rotating speed up to 
$1800 \mathrm{rpm}$ by advancing at $20 \mathrm{~mm} / \mathrm{min}$ for $316 \mathrm{~L} \mathrm{FSP}$ treatment. For processing of $2 \mathrm{~mm}$ thick plates made of the same $316 \mathrm{~L}$ steel, Chen et al. [46] applied the tool rotation speed in the range between 200 rpm and $315 \mathrm{rpm}$ with advancing velocity taken equal to $63 \mathrm{~mm} / \mathrm{min}$

The FSP process parameters were defined during the series of preliminary tests. In these tests, the rotation speed and advancing speed were varied from $50-100 \mathrm{~mm} / \mathrm{min}$ and 200-500 rpm correspondingly. Tilt angles $0^{\circ}, 1.5^{\circ}$ and $3^{\circ}$ were tested. The cold spray coating was extremely sensitive to the process parameters. Fragile coating failure in the zone of treatment was observed in most of the cases. It was found that processing at $\mathrm{V}=50 \mathrm{~mm} / \mathrm{min}, \mathrm{N}=300 \mathrm{rpm}$ and tilt angle $\mathrm{i}=1.5^{\circ}$ allowed to avoid the total failure of coating in the treatment zone. However, local coating delamination and failure at the nontreated zone at sample periphery was observed. At $\mathrm{V}=50 \mathrm{~mm} / \mathrm{min}, \mathrm{N}=300 \mathrm{rpm}$ and tilt angle equal to $0^{\circ}$, the coating integrity was also preserved, but the coatings had open defect related to the lack of mixing on the advancing side (Figure 8).

After series of preliminary tests, the FSP parameters set allowing to perform the coating treatment without coating delamination was established (Table 4). $F_{z}$ is the normal force applied during force control. Further structure analysis was performed for the samples produced using these FSP parameters.

Table 4: Optimized FSP parameters for treatment of Diamalloy 1003 coating.

\begin{tabular}{|llll|}
\hline$V$ & $N$ & $F_{z}$ & $i$ \\
\hline $50 \mathrm{~mm} / \mathrm{min}$ & $300 \mathrm{rpm}$ & $20 \mathrm{kN}$ & $1.5^{\circ}$ \\
\hline
\end{tabular}

\section{Results}

\subsection{Cross-section analysis of as-sprayed and FSP-treated deposits}

The cross-section micrographs of as-sprayed coatings taken at different magnifications are presented in Figure 9. Microscope observations did not reveal any cracks or other macroscale defects in the coating. The interface between the coating and substrate is well distinguishable, however no signs of coating delamination were observed. At the same time, the coating had high residual porosity well visible in the low-magnification cross-section image. The porosity value was not measured in this study, however high porosity of stainless steel cold spray deposits (up to $22 \%$ ) sprayed using nitrogen was previously reported by Villa et al. [11], Sova et al. [18] and Adachi et al. [47].

High-magnification images revealed that the coating had a typical structure for cold spray coating consisting in highly deformed stainless steel particles (splats) with visible interface. High porosity of the coating is explained by insufficient particle deformation and, as a consequence, weak bonding between splats. 
Friction stir processing significantly changed the structure of deposit. Typical cross-section image of the coating after FSP is provided in Figure 10. A difference in grey level allows to clearly identify the substrate and coating material. Cross-section observations show that the depth of material affected by FSP was significantly higher than the coating thickness. Taking into account the length of the pin (1.4mm), it is well seen that the stirring zone is deeper than the penetration depth of the pin. Therefore, the coatingsubstrate interface was affected by the FSP and the material transfer from the substrate to the coating is well visible. The material transfer was especially intensive in the advancing side where substrate material reached the top of the coating. Practically no defects were observed on the coating-substrate interface. At the same time, some cracks in the coating/substrate interface were detected in the regions not affected by FSP. The coating structure in the stirring zone was completely modified due to intense material deformation. No splats and inter-splat porosity are visible. It was also observed that the interface between the affected and non-affected zones was well distinguishable on the cross-section images after strong chemical etching, especially at advancing side (Figure 11).

\subsection{Microhardness}

The hardness map of coating is presented in Figure 12(a). One can see that the coating microhardness varied from less than $100 \mathrm{HV}$ to $550 \mathrm{HV}$. Such hardness variation could be explained by significant coating porosity. The maximum measured value $(598 \mathrm{HV})$ indicates strong work hardening of the particles during high-velocity impact and further plastic deformation. Elevated microhardness values in cold sprayed austenitic stainless steel coatings

were previously reported by Chen et al. [48]. The substrate microhardness was almost constant. The measured value were in the range $250-300 \mathrm{HV}$, in good correlation with nanohardness measurements of the substrate before coating deposition.

The microhardness map after FSP is presented in Figure 12(b). The coating microhardness was significantly decreased and homogenized in the FSP-affected zone. Hardness in almost the all zone lays in the range 300-350 HV. High microhardness values equal to 400-420 HV were measured in the area where the material transfer from substrate to coating was especially pronounced. However, these peak values was significantly lower than the maximum hardness measured in as-sprayed deposit (598 HV). The micro-hardness in the non-affected parts of the coating was higher than in the FSP affected zone (with the peak values $~ 550 \mathrm{HV}$ ).

\subsection{EBSD analysis on CSD-NSD plane}

Figure 13 presents the EBSD measurements on the Cross Stirring Direction (CSD)-Normal Stirring Direction (NSD) plane in the as-sprayed coatings confirmed the presence of high number of small grains inside the splats that is typical for cold spray deposits. The interface between substrate and coating is well distinguishable on the EBSD image due to significantly higher grain size and absence of sub-grains in the substrate material as presented in Figure 13(b). In addition, Figure 13 (c) reveals the presence of 
sub-grains in the coating through local EBSD map in the coating corresponding to the white dashed region in Figure 13 (b) that could be explained by strong particle material deformation at impact.

EBSD maps made on different zones of the coating after FSP are shown in Figure 14. The images were obtained on the intersection plane perpendicular to the advancing direction. A very clear microstructure made of small grains with grain size of about $1.9 \mathrm{~mm}$ with almost no substructure nor twin boundaries is revealed, supporting the idea that the material dynamically recrystallize during FSP. The grain structure in the treated coating and in the substrate were very similar with the consequence that the coating/substrate interface could not be clearly identified as the respective grain sizes of these regions are similar: the average grain sizes measured in the affected zone of the coating and in the substrate were $1.9 \mathrm{~mm}$ and $2.5 \mathrm{~mm}$, respectively.

Pole figures (f100g, $\mathrm{f} 110 \mathrm{~g}$ and $\mathrm{f} 111 \mathrm{~g}$ planes) obtained from EBSD maps are illustrated in Figure 15 in the reference frame of FSP, i.e. stirring direction, cross stirring direction, and normal stirring direction. Texture differences were not found between the half-thick of coating and the interface with the substrate. This observation confirms that recrystallization process was similar across the coating thickness.

\section{Discussion}

The experiments presented above demonstrated the feasibility of FSP of austenitic stainless steel cold spray deposits with thickness superior to $1 \mathrm{~mm}$. At the same time, several important issues influencing the process reliability were identified. The fragile failure of the coating at the periphery was regularly observed. This phenomenon could be explained by the structure of cold spray deposit (Figure 16). Any metallic cold spray deposit has specific two-level structure where severely deformed metal particles (splats) are in close contact. Each splat has a normal grain structure, with larger grains at the splat center and smaller grains at the splat periphery. The interface between splats has complex structure containing subgrains, dislocations, pores and oxides $[5,6]$. It is also known that the cohesive strength of the cold spray coating is mainly defined by the quality of the contact between splats. The micro-tensile tests revealed that the ductility of the material in the splat/splat contact is very low in comparison with the primary material in the splat center. In addition, the ultimate tensile strength of the core splat material is also higher than the cohesive strength between splats $[6,49]$. Consequently, during the tensile and compressive tests in macroscale, the fragile failure of deposits at the splat boundaries is regularly observed.

During the FSP treatment, high normal load and shear stress in the stir zone rapidly induces the viscoelastic ow of material in the splats. The fragile failure in the stir zone is avoided due to rapid material recrystallization, erasing the splat boundaries and forming uniform small-grains structure (Figure 17). The coating adhesion to the substrate is also improved by intensive material mixing and recrystallization at the coating/substrate interface.

At the same time, the coating periphery also experiences strong rise of the stress induced by the tool (lateral forces, torque as well as thermal stresses). However, in contrast to the stir zone, the material 
recrystallization at the periphery does not occur and the deposit keeps the initial two-level structure. As a consequence, if the tool-induced stresses become higher than the tensile strength of the splat/splat and splat/substrate contact, the coating failures. Two types of failures can happened and have been experimentally observed: cohesive failure at the splat/splat interface characterized by cracks propagation in the coating and adhesive failure at the splat/substrate interface noticed as a delamination of the whole coating.

The obvious way to avoid the coating failure is to increase the coating tensile and adhesive strength. It is known, that the mechanical properties of the cold spray coating depend on the particle impact velocity and temperature. In general, increase of these parameters allows to improve the coating UTS and adhesive strength. Assadi et al. [6] introduced the parameter $\eta$ characterizing the ratio between critical velocity and particle impact velocity:

$$
\eta=\frac{v_{\text {imact }}}{v_{\text {critical }}}
$$

Critical velocity $v_{\text {critical }}$ is the minimal velocity that the particle should have in order to bond to the substrate. Authors also showed that the highest possible cohesive and adhesive strength of the coating corresponding to the strongest splat/splat contact is achieved if the lays in the range 1.5-1.8 [6]. It is also known, that in case of spraying of $316 \mathrm{~L}$ powder with nitrogen as the working gas at the maximum possible spraying parameters $(P=50$ bars, $T=800 \circ C)$, the $\eta$ parameter does not exceed 1.25 [6]. Thus, significant improvement of adhesive and cohesive strength of the austenitic stainless steel cold spray coating is not achievable if the nitrogen is used as the working gas. Usage of helium instead of nitrogen allows to increase the impact particle impact velocity almost in two times under similar gas stagnation temperature and pressure [4]. The UTS of the coating sprayed with helium could be similar to the reference value obtained for bulk material. For example, Coddet et al. [15] reported that UTS of 304L stainless steel coating sprayed with helium at 28 bars and $500^{\circ} \mathrm{C}$ was near $600 \mathrm{MPa}$. However, the usage of the helium significantly increase the cost that reduces the industrial interest to this option [7].

Another approach that potentially could minimize the risk of coating failure is the progressive coating deposition with consecutive FSP treatment. One can propose that the FSP treatment should be applied at moment when the coating width does not exceed the diameter of FSP tool. The coating width could be further increased by the consecutive deposition and immediate FSP treatment of single coating lines attached to the FSP-treated zone. This approach is schematically illustrated in Figure 18.

\section{Conclusion}

In this study the feasibility study of friction stir processing of $1.5 \mathrm{~mm}$ austenitic stainless steel cold spray coatings deposited on 304L stainless steel substrate was performed. Taking into account the obtained results, the following conclusions could be drawn: 
- Friction stir processing of relatively thick $(1.5 \mathrm{~mm})$ austenitic stainless steel cold spray coating is feasible. Approximate parametric window of FSP treatment was experimentally determined.

However, further parameter optimization as well as the treatment strategy should be done in order to avoid the coating failure during treatment. The issue with the tool heating during treatment should be also resolved by application of proper cooling system.

- The depth of the zone affected by FSP treatment was slightly higher than the coating thickness. The mixing of the substrate and the coating material at the interface was observed. This effect should significantly influence on the adhesive strength of the coating. However, the detailed analysis of the adhesive strength was not performed in this study.

- Material recrystallization in the stir zone allowed to modify the coating microstructure. Instead of splat structure with significant amounts of pores and defects, a uniform _ne-grain structure was formed. The microhardness maps confirm remarkable improvement of the uniformity of coating microstructure in comparison of as-built coating.

- Further research should be devoted to the investigation of the coating material properties after FSP treatment. In particular, the mechanical properties of the coating as well as the bonding strength should be analyzed.

\section{Declarations}

Ethics approval

Not applicable

\section{Consent to participate}

Not applicable

\section{Consent for publication}

Not applicable

\section{Authors contributions}

T. Perard: Conceptualization, Methodology, Experimental investigation, Formal analysis

A. Sova: Conceptualization, Methodology, Experimental investigation, Formal analysis, Writing - Original Draft

H. Robe: Conceptualization, Methodology, Formal analysis, Writing - Original Draft

V. Robin: Conceptualization, Methodology, Supervision

Y. Zedan: Experimental investigation, Formal analysis, Writing - Original Draft 
P. Bocher: Methodology, Formal analysis

E. Feulvarch: Conceptualization, Methodology, Formal analysis, Supervision, Writing - Original Draft

\section{Funding}

No funding was received for conducting this study

\section{Competing Interests}

The authors have no conflict of interest to declare that are relevant to the content of this article

\section{Availability of data and material}

The authors declare that all data supporting the findings of this study are available within the article. No supplementary data are available.

\section{Code availability}

Not applicable

\section{References}

1. Lijun Song, Guangcheng Zeng, Hui Xiao, Xianfeng Xiao, Simeng Li, Repair of 304 stainless steel by laser cladding with $316 \mathrm{~L}$ stainless steel powders followed by laser surface alloying with WC powders, Journal of Manufacturing Processes, Volume 24, Part 1, 2016, Pages 116-124.

2. Xin Lin, Yongqing Cao, Xiaoyu Wu, Haiou Yang, Jing Chen, Weidong Huang, Microstructure and mechanical properties of laser forming repaired 17-4PH stainless steel, Materials Science and Engineering: A, Volume 553, 2012, Pages 80-88.

3. Gunter, M.P. Miles, F.C. Liu, T.W Nelson, Solid state crack repair by friction stir processing in 304L stainless steel, Journal of Materials Science \& Technology 34 (2018) 140-147.

4. Papyrin, V. Kosarev, S. Klinkov, A. Alkhimov, V. Fomin, Cold Spray Technology, Elsevier Science, Amsterdam, ISBN: 9780080451558, (2007).

5. K. Champagne, The cold spray materials deposition process: Fundamentals and applications, ISBN: 9781845691813, (2007)

6. Assadi, H. Kreye, F. Gartner, T. Klassen, Cold spraying A materials perspective, Acta Materialia, 116, (2016), 382-407.

7. Vilafuerte, Modern Cold Spray: theory process and applications, Springer International Publishing, Switzerland, ISBN 978-3-319-16772-5, (2015).

8. Champagne, D. Helfritch (2015), Critical Assessment: Structural repairs by cold spray, Materials Science and Technology, 31:6, 627-634. 
9. Yandouzi, S. Gaydos, D. Guo., R. Ghelichi, B. Jodoin, Aircraft Skin Restoration and Evaluation. J Therm Spray Tech 23, 12811290 (2014).

10. N. Raoelison, C. Verdy, H. Liao, (2017). Cold gas dynamic spray additive manufacturing today: Deposit possibilities, technological solutions and viable applications. Materials \& Design, 133, 266287.

11. Villa, S. Dosta, J.M. Guilemany (2013), Optimization of 316L stainless steel coatings on light alloys using Cold Gas Spray, Surface \& Coatings Technology, vol. 235, p.220-225.

12. Burak Dikici, Mehmet Topuz, Production of Annealed Cold-Sprayed 316L Stainless Steel Coatings for Biomedical Applications and Their in-vitro Corrosion Response Protection of Metals and Physical Chemistry of Surfaces, 2018 , Vol. 54, No. 2, pp. 333-339.

13. N. Brewer, J.F. Schiel, E.S.K. Menon, D.J. Woo, The connections between powder variability and coating microstructures for cold spray deposition of austenitic stainless steel, Surface and Coatings Technology, Volume 334, 2018, 50-60.

14. Shuo Yin, Xingchen Yan, Richard Jenkins, Chaoyue Chen, Marios Kazasidis, Min Liu, Min Kuang, Rocco Lupoi, Hybrid additive manufacture of 316L stainless steel with cold spray and selective laser melting: Microstructure and mechanical properties, Journal of Materials Processing Technology, Volume 273, 2019,116248.

15. Pierre Coddet, Christophe Verdy, Christian Coddet, Franois Debray, Florence Lecouturier, Mechanical properties of thick 304L stainless steel deposits processed by He cold spray, Surface and Coatings Technology, Volume 277, 2015, Pages 74-80.

16. Xie, M. Planche, R. Raoelison, H. Liao, X. Suo, P. Herve, effect of Substrate Preheating on Adhesive Strength of SS 316L Cold Spray Coatings. J Therm Spray Tech 25, 123-130 (2016).

17. Xianming Meng, Junbao Zhang, Jie Zhao, Yongli Liang, Yujun Zhang, Influence of Gas Temperature on Microstructure and Properties of Cold Spray 304SS Coating, Journal of Materials Science \& Technology, Volume 27, Issue 9, 2011, 809-815.

18. Sova, S. Grigoriev, A. Okunkova, I. Smurov (2013), Cold spray deposition of 316L stainless steel coatings on aluminum surface with following laser post-treatment, Surface \& Coatings Technology, vol. 235, p.283-289.

19. Spencer, MX. Zhang, Optimization of stainless steel cold spray coatings using mixed particle size distributions, Surface \& Coatings Technology. 205 (2011) 5135-5140.

20. Sun, A.-Y. Tan, K. Wu, S. Yin,X. Yang, I. Marinescu, E. Liu, Post Process Treatments on Supersonic Cold Sprayed Coatings: A Review. Coatings'2020, 10, 123.

21. Shuo Yin, Jan Cizek, Xingchen Yan, Rocco Lupoi (2019), Annealing strategies for enhancing mechanical properties of additively manufactured $316 \mathrm{~L}$ stainless steel deposited by cold spray, Surface \& Coatings Technology, 370, p.353-361.

22. Huang, M. Sone, W. Ma, H. Fukanuma, The effects of heat treatment on the mechanical properties of cold-sprayed coatings. Surf. Coat. Technol. 2015, 261, 278-288 
23. R. Rokni, C.A. Widener, V.K. Champagne, G.A. Crawford, Microstructure and mechanical properties of cold sprayed 7075 deposition during non-isothermal annealing. Surf. Coat. Technol. 2015, 276, 305315.

24. Petrovskiy, A. Sova, M. Doubenskaia, I. Smurov, Influence of hot isostatic pressing on structure and properties of titanium cold-spray deposits. Int. J. Adv. Manuf. Technol. 2019, 102, 819-827.

25. Nandan, T. DebRoy, H.K.D.H. Bhadeshia, Recent Advances in Friction-Stir Welding: Process, Weldment Structure and Properties, Prog. Mater Sci., 2008, 53(6), p 980-1023.

26. S. Mishra and Z.Y. Ma, Friction Stir Welding and Processing, Mater. Sci. Eng. R, 2005, 50(1-2), p 1-78.

27. R. McNelley, S. Swaminathan, and J.Q. Su, Recrystallization Mechanisms During Friction Stir Welding/Processing of Aluminum Alloys, Scr. Mater., 2008, 58(5), p 349-354.

28. Khodabakhshi, A. Simchi, A.H. Kokabi, A.P. Gerlich, and M.Nosko, Effects of Stored Strain Energy on Restoration Mechanisms and Texture Components in an Aluminum-Magnesium Alloy Prepared by Friction Stir Processing, Mater. Sci. Eng. A, 2015, 642, p 204-214.

29. Oh-Ishi et T. R. McNelley, Microstructural modification of as-cast NiAl bronze by friction stir processing, Metall and Mat Trans A, vol. 35, no9, p. 29512961, sept. 2004.

30. Y. Ma, A. L. Pilchak, M. C. Juhas, et J. C. Williams, Microstructural refinement and property enhancement of cast light alloys via friction stir processing, Scripta Materialia, vol. 58, no5, p. 361366, mars 2008.

31. Juan Guillermo Santos Macas et al., Ductilisation and fatigue life enhancement of selective laser melted AlSi10Mg by friction stir processing, Scripta Materialia, Volume 170, (2019), 124-128.

32. S. Rezaei-Nejad, A. Abdollah-zadeh, M. Hajian, F. Kargar, et R. Seraj, Formation of Nanostructure in AISI 316L Austenitic Stainless Steel by Friction Stir Processing, Procedia Materials Science, vol. 11, p. 397402, 2015.

33. J. Hodder, H. Izadi, A. G. McDonald, A. P. Gerlich, Fabrication of aluminum alumina metal matrix composites via cold gas dynamic spray at low pressure followed by friction stir processing, Materials Science \& Engineering A 556 (2012) 114-121.

34. Kang Yang, Wenya Li, Yaxin Xu, Xiawei Yang, Using friction stir processing to augment corrosion resistance of cold sprayed AA2024/Al2O3 composite coatings, Journal of Alloys and Compounds.

35. Kang Yang, Wenya Li, Chunjie Huang, Xiawei Yang, Yaxin Xua, Optimization of cold-sprayed AA2024/Al203metal matrix composites via friction stir processing: Effect of rotation speeds, Journal of Materials Science \& Technology (2018).

36. Khodabakhshi, B. Marzbanrad, L.H. Shah, H. Jahed, A.P. Gerlich, Friction-stir processing of a cold sprayed AA7075 coating layer on the AZ31B substrate: Structural homogeneity, microstructures and hardness, Surface \& Coatings Technology.

37. Chunjie Huang, Wenya Li, Zhihan Zhang, Marie-pierre Planche, Hanlin Liao, and Ghislain Montavon, Effect of Tool Rotation Speed on Microstructure and Microhardness of Friction-Stir-Processed ColdSprayed SiCp/ Al5056 Composite Coating, Journal of Thermal Spray Technology. 
38. Chunjie Huang, Wenya Li, Yan Feng, Yingchun Xie, Marie-Pierre Planche, Hanlin Liao, Ghislain Montavon, Microstructural evolution and mechanical properties enhancement of a cold-sprayed CuZn alloy coating with friction stir processing, Materials Characterization 125 (2017) 76-82.

39. J. Huang, X.C. Yan, W.Y. Li, W.B. Wang, C. Verdy, M.P. Planche, H.L. Liao, G. Montavon Post-spray modification of cold-sprayed $\mathrm{Ni}$-Ti coatings by high-temperature vacuum annealing and friction stir processing, Applied Surface Science.

40. Khodabakhshi, B. Marzbanrad, L. H. Shah, H. Jahed, A. P. Gerlich, Surface Modification of a Cold Gas Dynamic Spray-Deposited Titanium Coating on Aluminum Alloy by using Friction-Stir Processing, Journal ofi Thermal Spray Technology volume 28, pages11851198 (2019).

41. Tom Peat, Alexander Galloway, Athanasios Toumpis, Russell Steel, Wenzhong Zhu, Naveed Iqbal, Enhanced erosion performance of cold spray co-deposited AISI316MMCs modified by friction stir processing, Materials and Design 120 (2017) 22-35.

42. Tom Peat, Alexander Galloway, Athanasios Toumpis, Philip McNutt, Naveed Iqbal, The erosion performance of cold spray deposited metal matrix composite coatings with subsequent friction stir processing, Applied Surface Science Volume 396, 28 February 2017, Pages 1635-1648.

43. P. Miles, T.W. Nelson, C. Gunter, F.C. Liu, L. Fourment, T. Mathis, Predicting recrystallized grain size in friction stir processed 304L stainless steel, Journal of Materials Science \& Technology 35 (2019) 491-498.

44. Karthikeyan Selvam, Priya Mandal, Harpreet Singh Grewal, Harpreet Singh Arora, Ultrasonic cavitation erosion-corrosion behavior of friction stir processed stainless steel, Ultrasonics Sonochemistry 44 (2018) 331- 339.

45. Hajian, A. Abdollah-zadeh, S.S. Rezaei-Nejad, H. Assadi, S.M.M. Hadavi, K. Chung, M. Shokouhimehr, Microstructure and mechanical properties of friction stir processed AISI 316 L stainless steel, Materials and Design 67 (2015) 82-94.

46. C. Chen, H. Fujii, T. Tsumura, Y. Kitagawa, K. Nakata, K. Ikeuchi, K. Matsubayashi, Y. Michishita, Y. Fujiya, J. Katoh, Banded structure and its distribution in friction stir processing of $316 \mathrm{~L}$ austenitic stainless steel, Journal of Nuclear Materials 420 (2012) 497-500.

47. Shinichiro Adachi and Nobuhiro Ueda (2017), Effect of Cold-Spray Conditions Using a Nitrogen Propellant Gas on AISI 316L Stainless Steel Coating Microstructures, Coatings, 7, 87; doi:10.3390/coatings7070087.

48. Jie Chen, Bing Ma, Guang Liu, Hui Song, Jinming Wu, Lang Cui, Ziyun Zheng (2017), Wear and Corrosion Properties of 316L-SiC Composite Coating Deposited by Cold Spray on Magnesium Alloy, Thermal Spray Technology, 26, pages1381-1392.

49. Ichikawa Y., Tokoro R., Ogawa K. (2016), Micro-Scale Strength Evaluation for Bonding Interface of Cold Sprayed Coatings. Materials Science Forum, 879, 795-800.

\section{Figures}



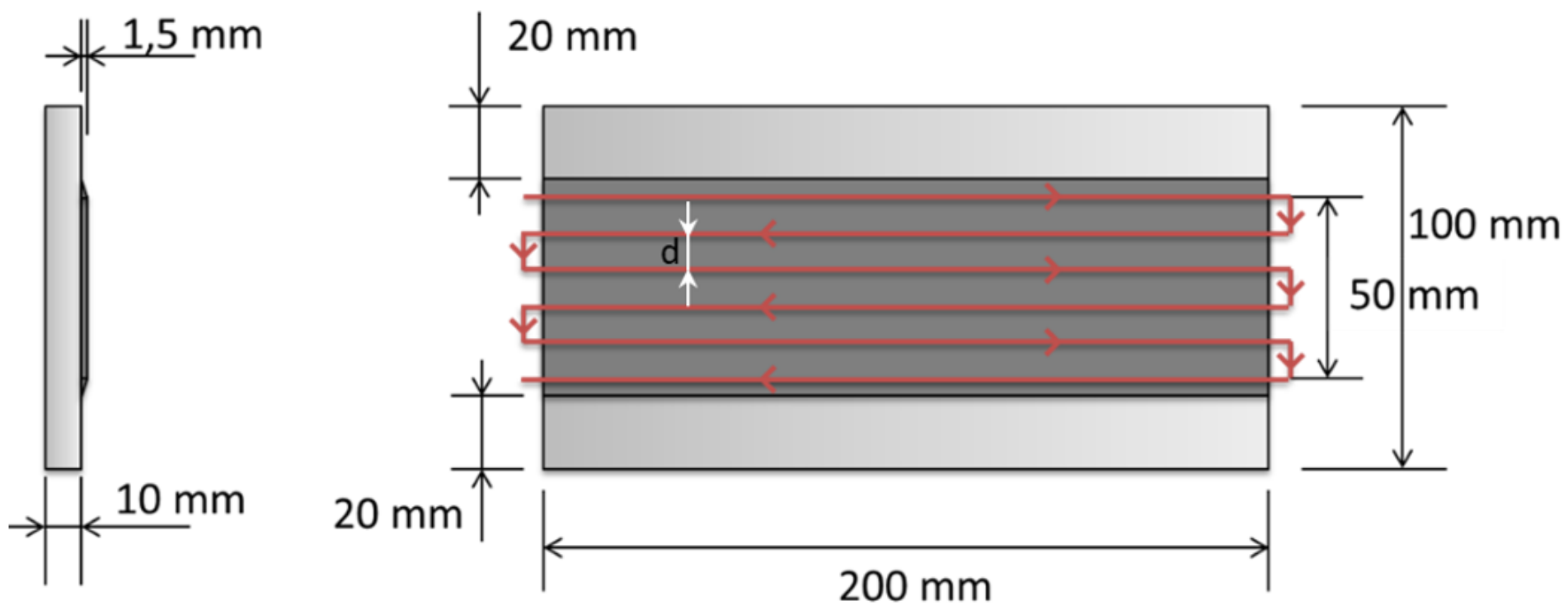

Figure 2

Samples dimensions and the nozzle displacement strategy applied for coating deposition
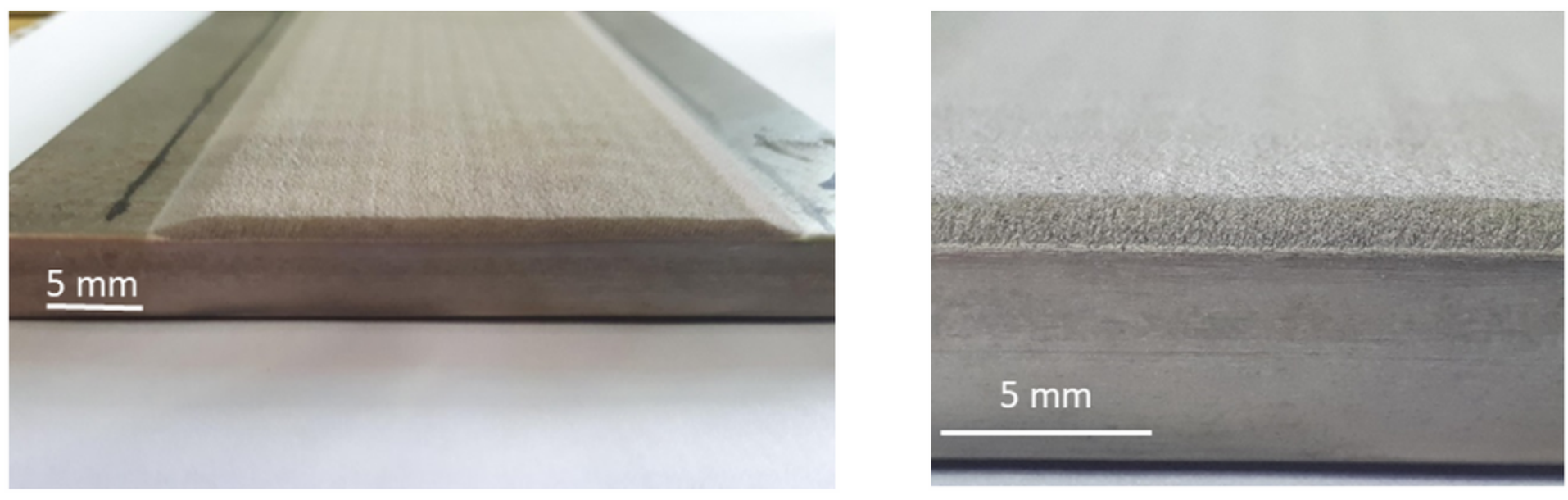

Figure 3

Overview of the Diamalloy 1003 cold spray coating deposited on the $304 \mathrm{~L}$ substrate 

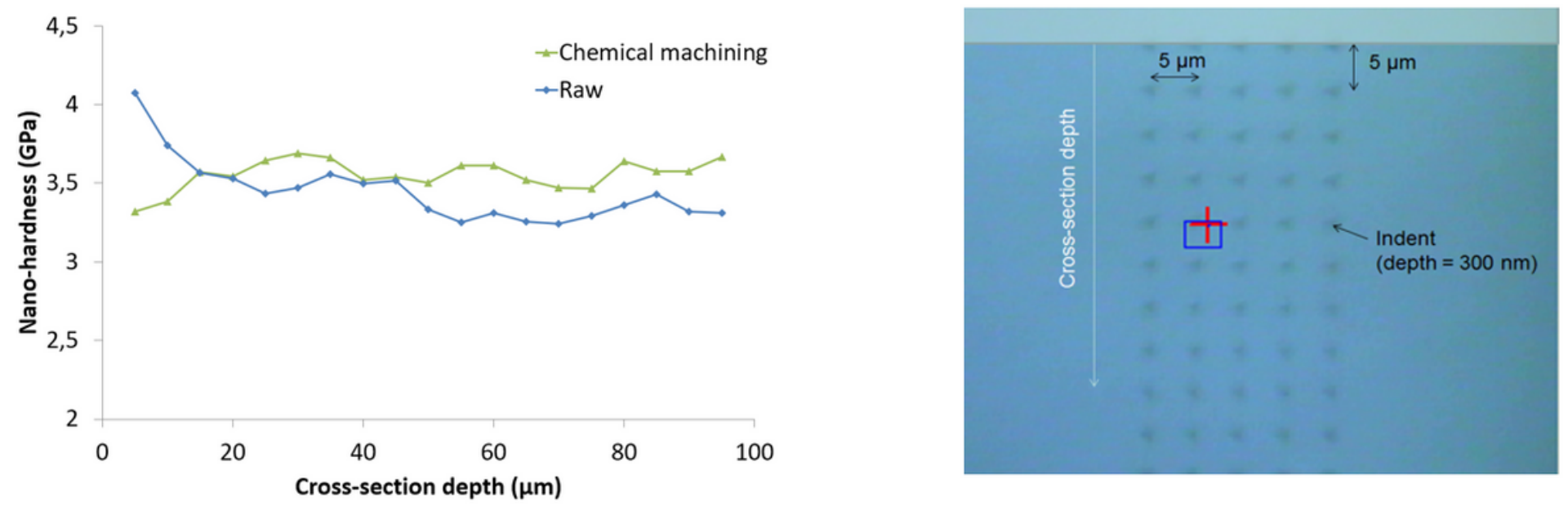

\section{Figure 4}

Results of nanohardness measurements performed in the near-surface zone of the substrate

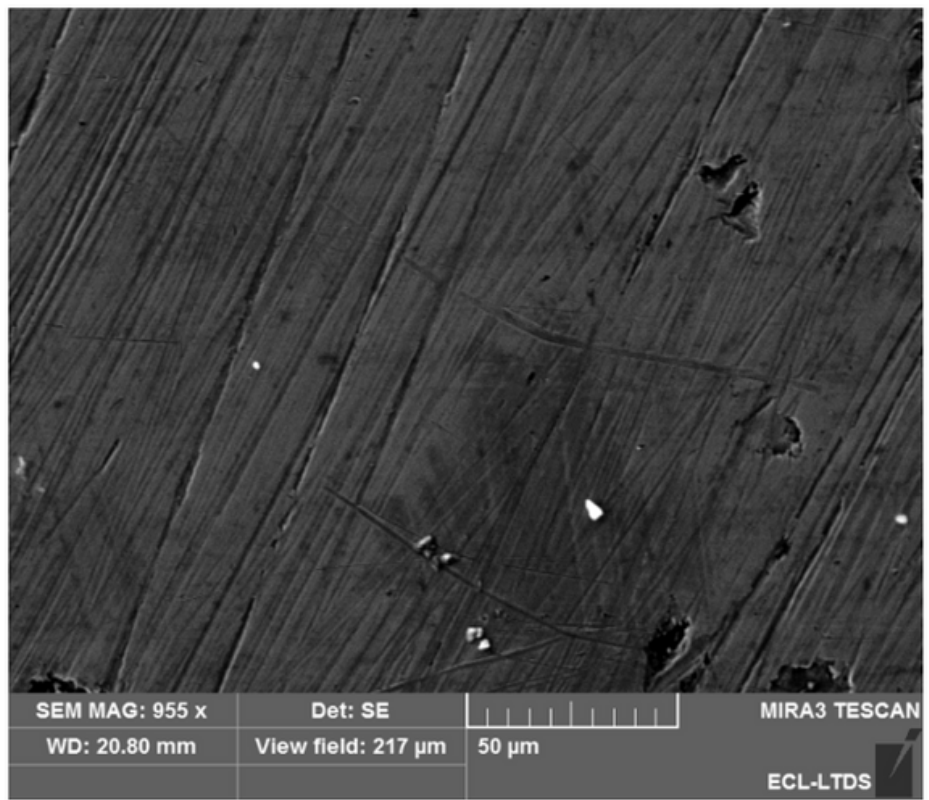

a

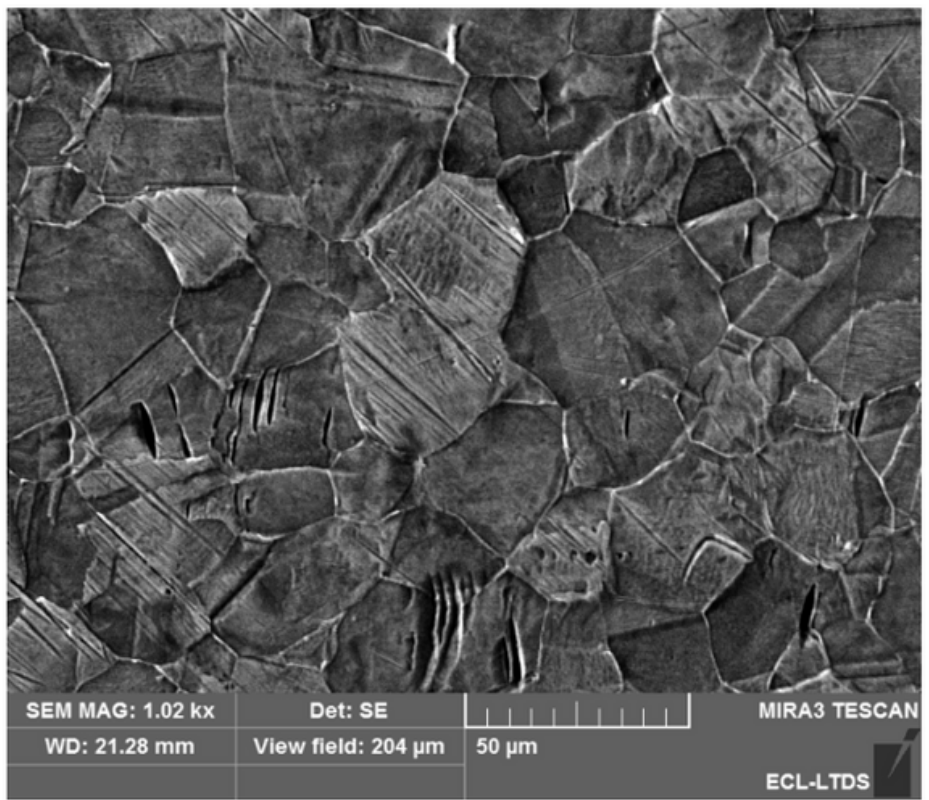

b

\section{Figure 5}

SEM images of the substrate surfaces; (a) - raw substrate after acetone cleaning (b) substrate after chemical machining 
a)

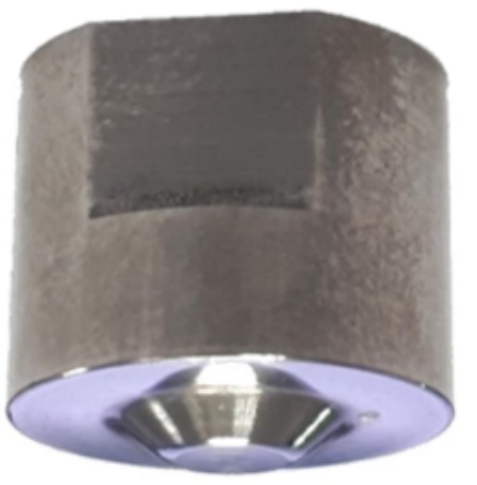

$0,5 \mathrm{~mm}$
$15 \mathrm{~mm}$

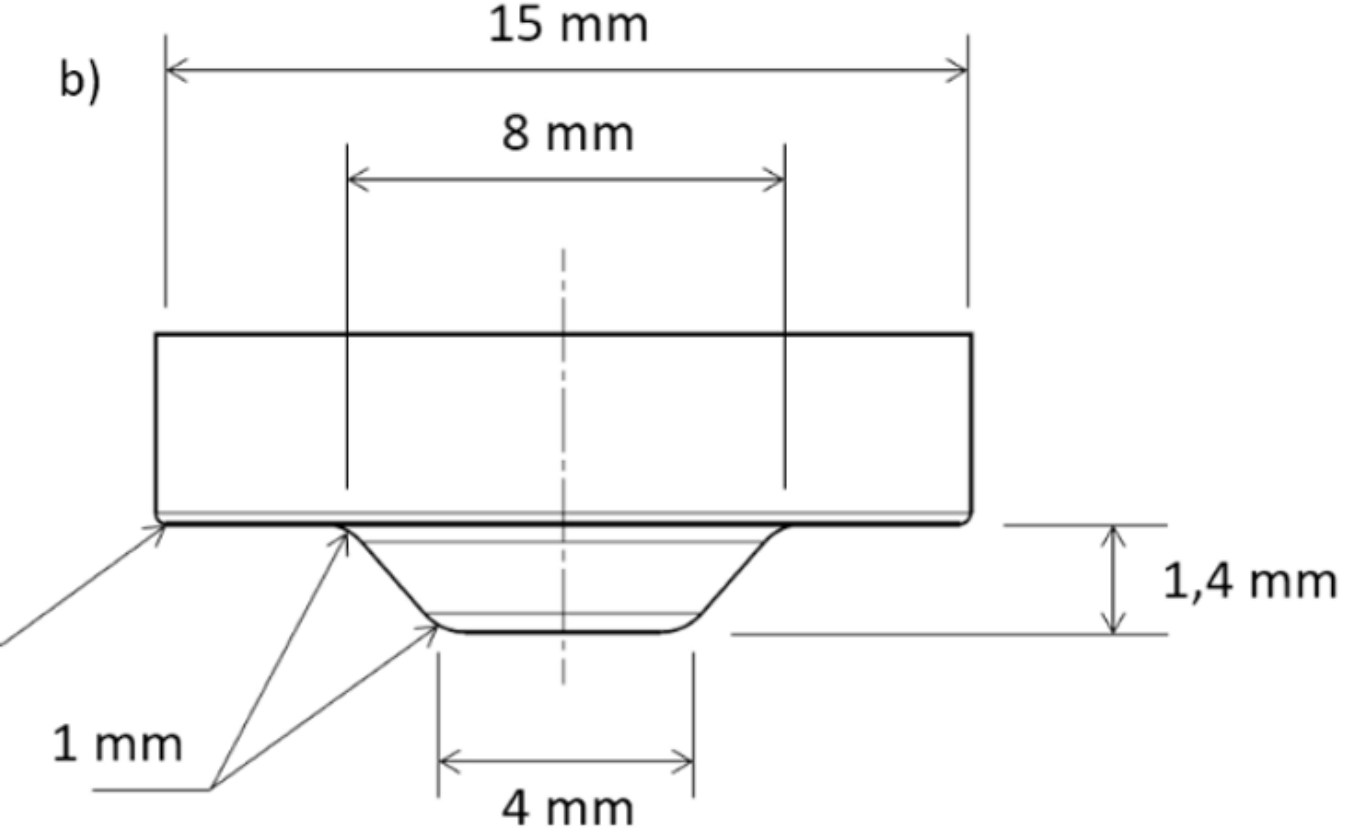

Figure 6

Overview (a) and dimensions (b) of FSP tool used for the treatment of cold spray Diamalloy 1003 coating
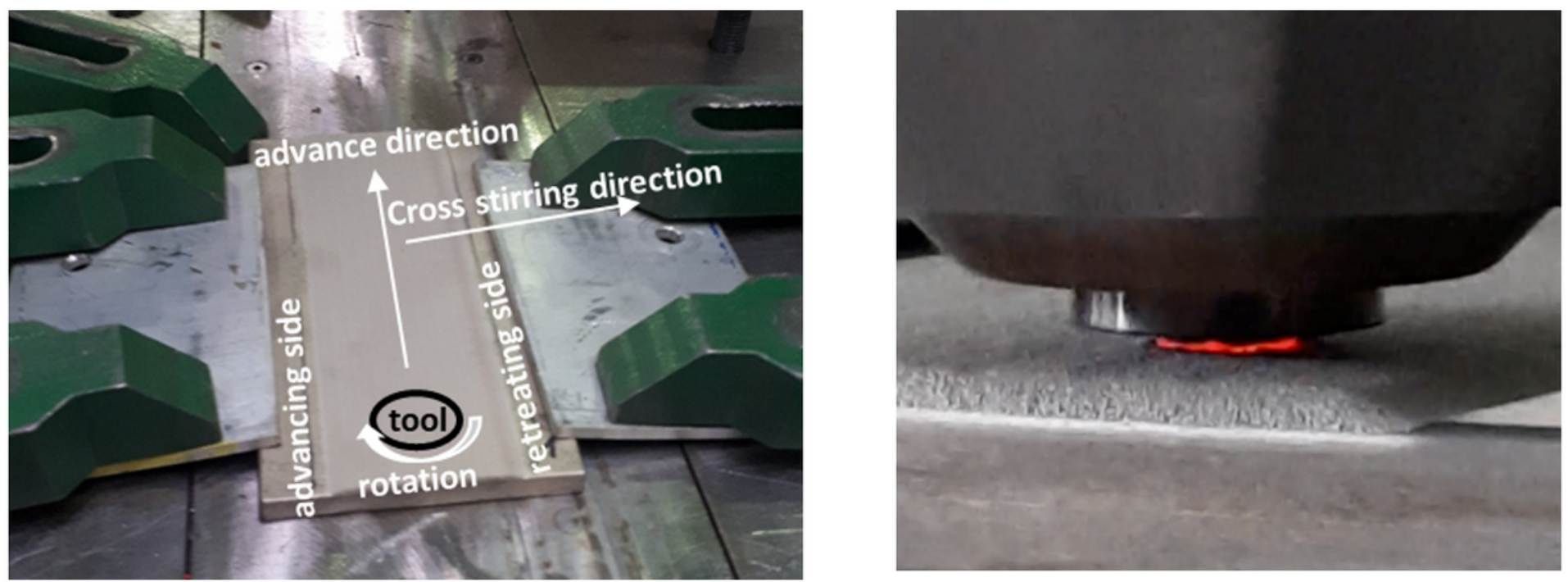

Figure 7

Sample positioning for FSP treatment 


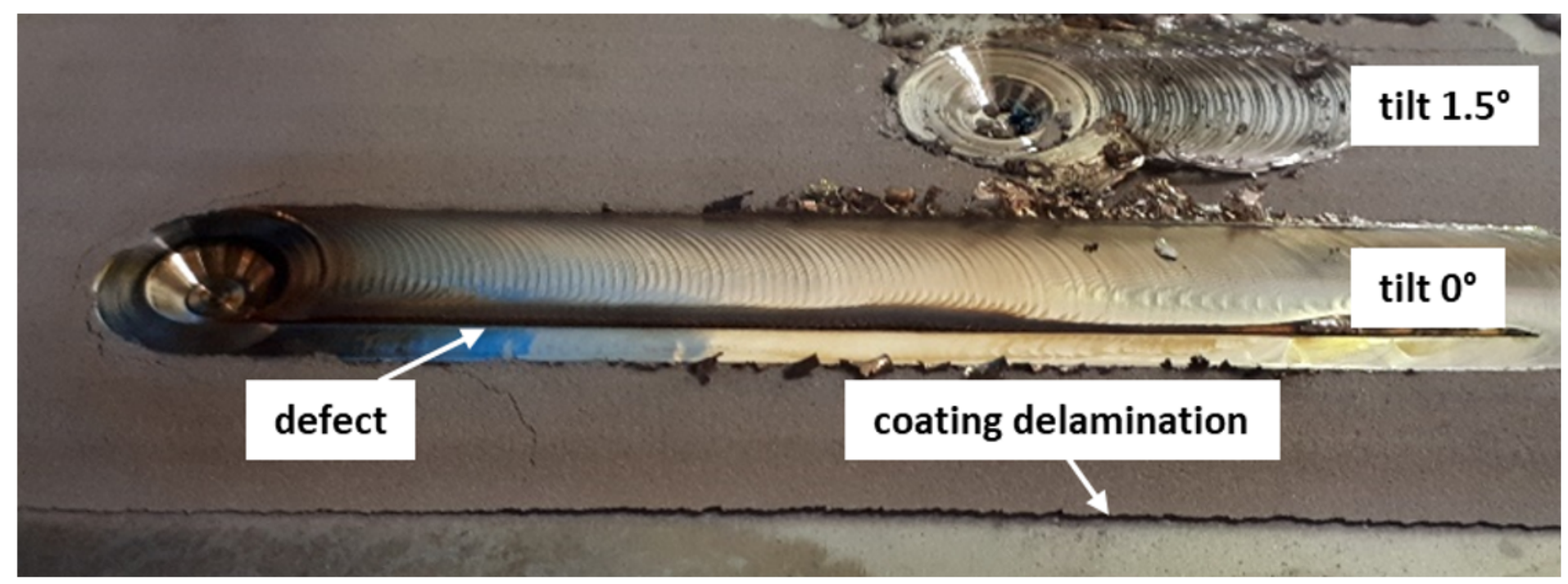

\section{Figure 8}

The coating overview after single pass of FSP treatment at $\mathrm{V}=50 \mathrm{~mm} / \mathrm{min}, \mathrm{N}=300 \mathrm{rpm}, \mathrm{Fz}=20 \mathrm{kN}$ and tilt angles $1.5^{\circ}$ and $0^{\circ}$

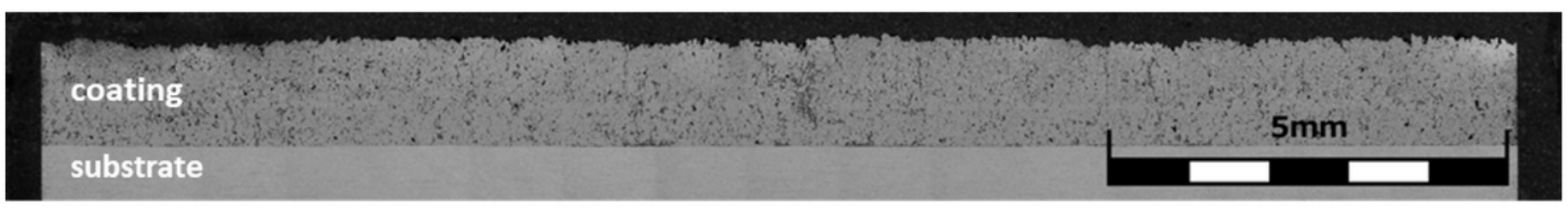

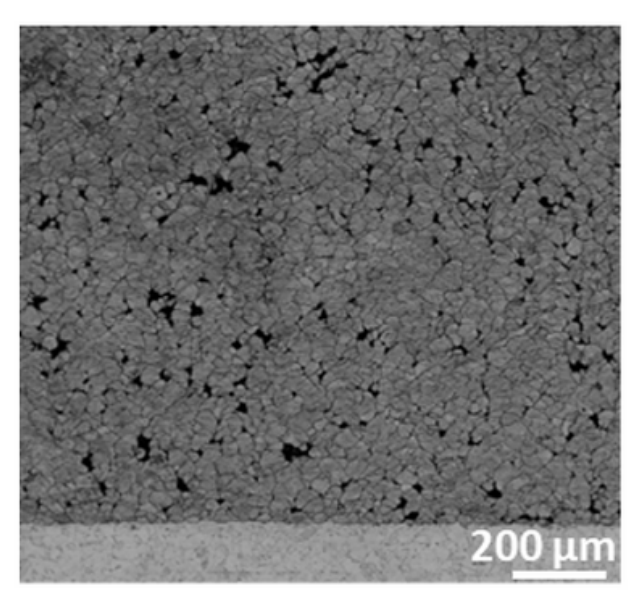

b

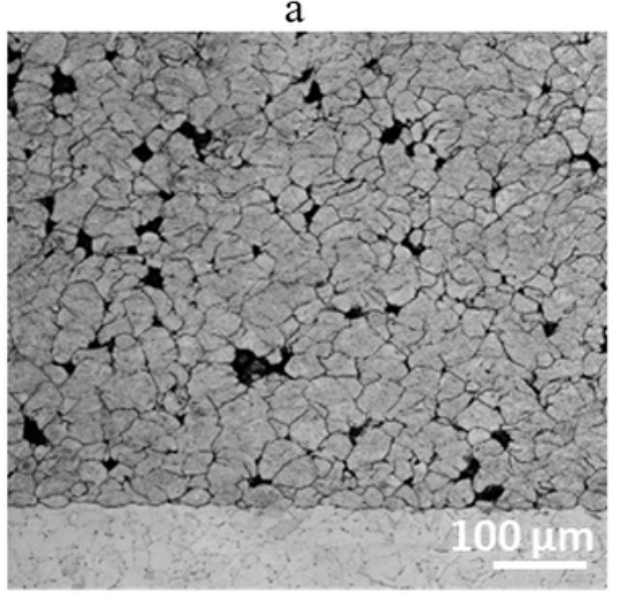

c

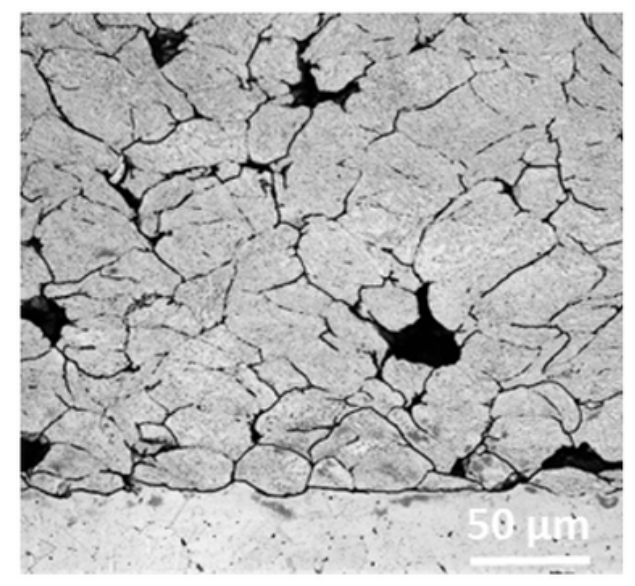

d

\section{Figure 9}

Cross-section optical images of as-sprayed Dimalloy 1003 coatings on the 304L substrate at different magnifications: (a) overview; (b) x100; (c) x200; (d) x500 


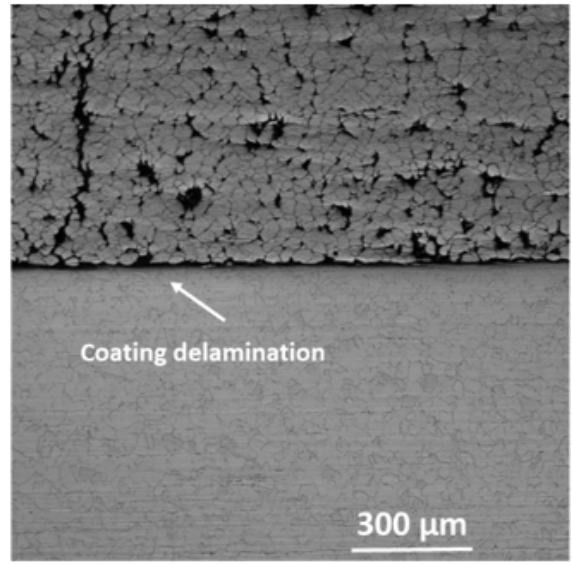

b

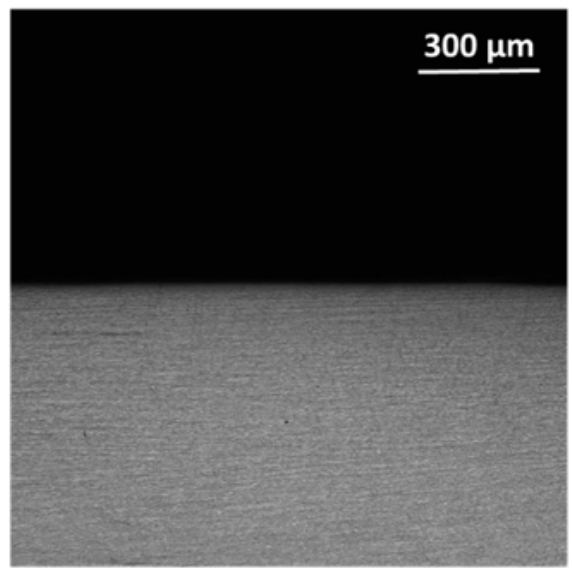

C

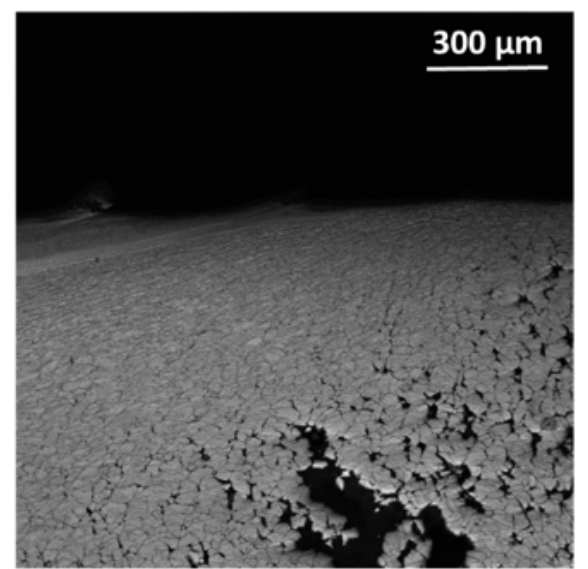

d $\quad$

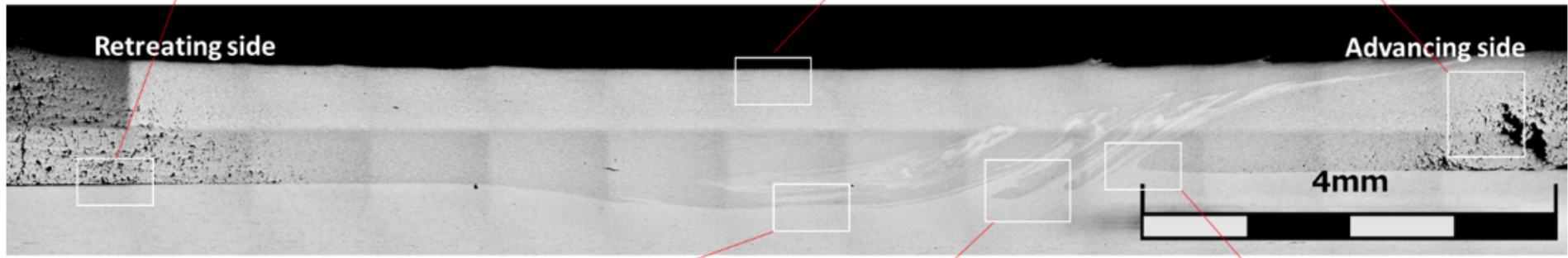

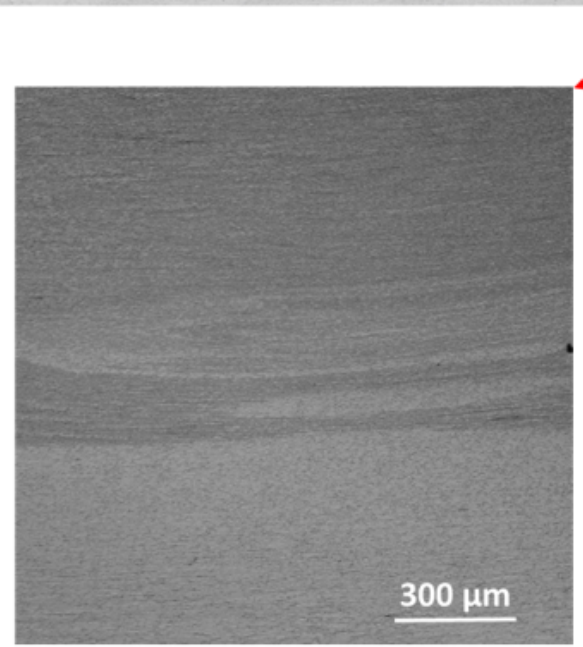

e a

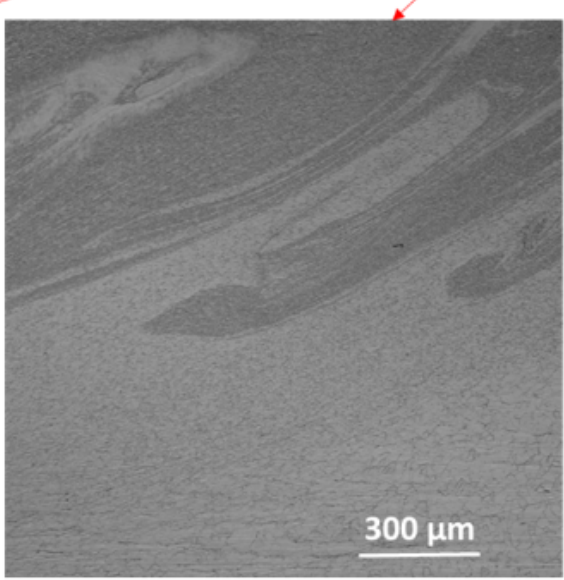

f

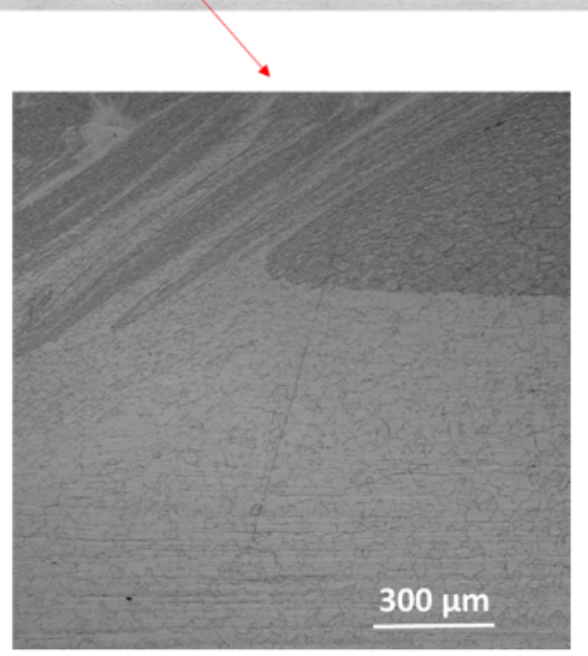

g

\section{Figure 10}

Cross-section micrographs of Diamalloy 1003 coatings on the 304L substrate after FSP; (a) - general view, (b) - adhesive failure at the coating periphery, (c) - top zone of the treated coating; (d) - cohesive failure at the coating periphery; (e) - coating-substrate interface at the stir zone; (d), (e) - zones with substrate/coating material mixing 


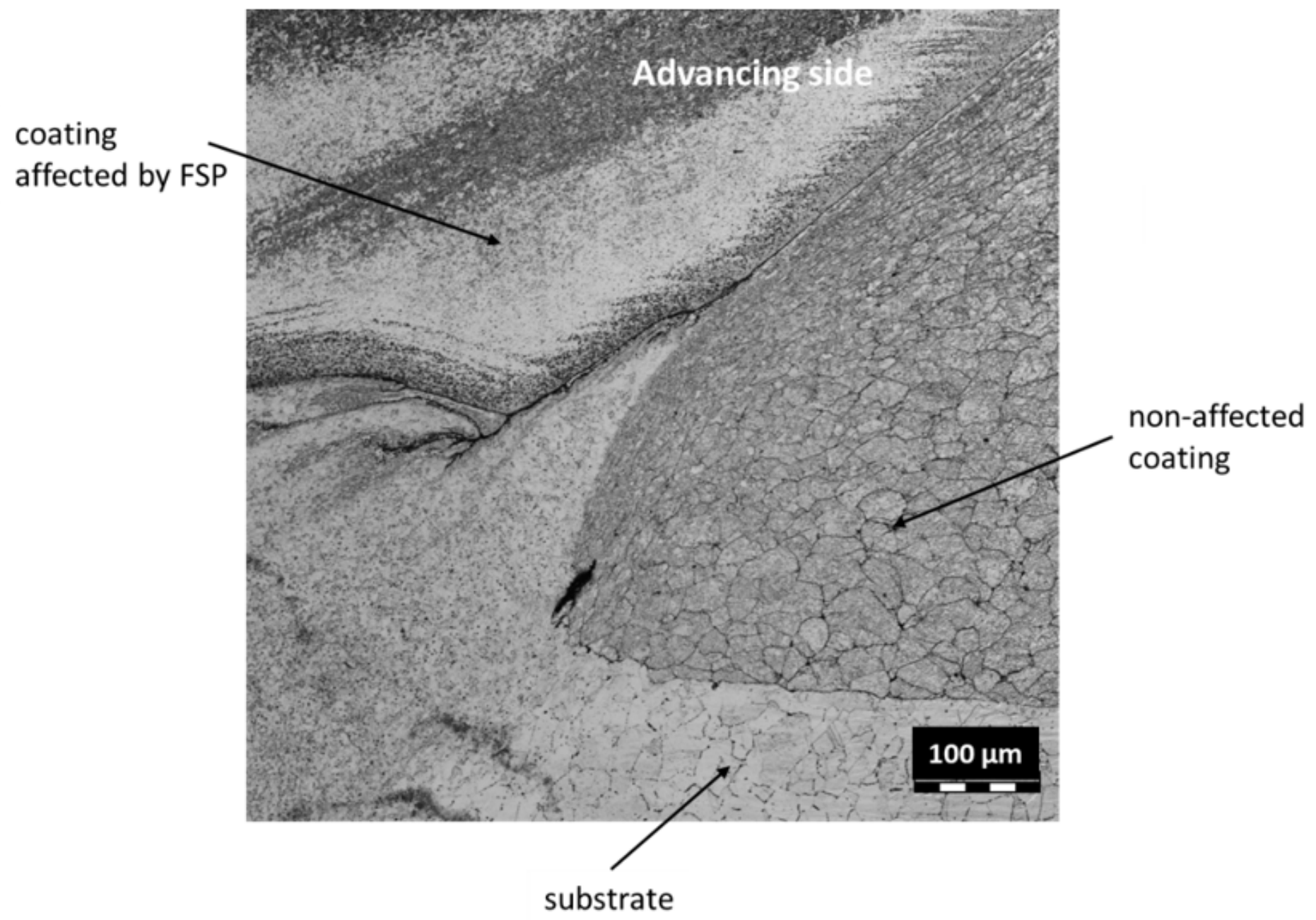

\section{Figure 11}

Cross-section micrographs of Diamalloy 1003 coatings on the 304L substrate after FSP taken at the interface between affected and non-affected zones of the coating 

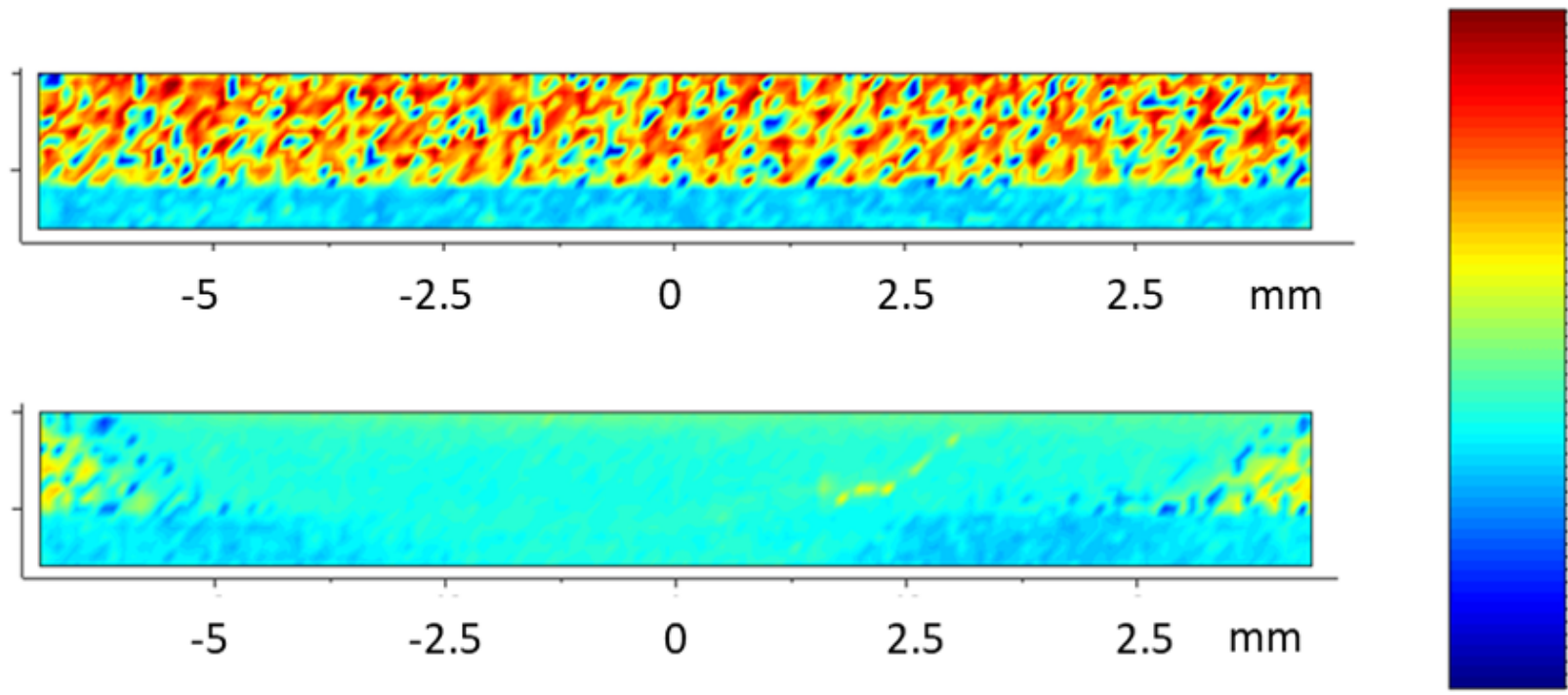

600

550

500

450

400

350

300

250

200

150

$\begin{array}{llllll}-5 & -2.5 & 0 & 2.5 & 2.5 & \mathrm{~mm}\end{array}$

100

Figure 12

Microhardness of the as-sprayed (a) and FSP-treated (b) Diamalloy 1003 coatings on the 304L substrate

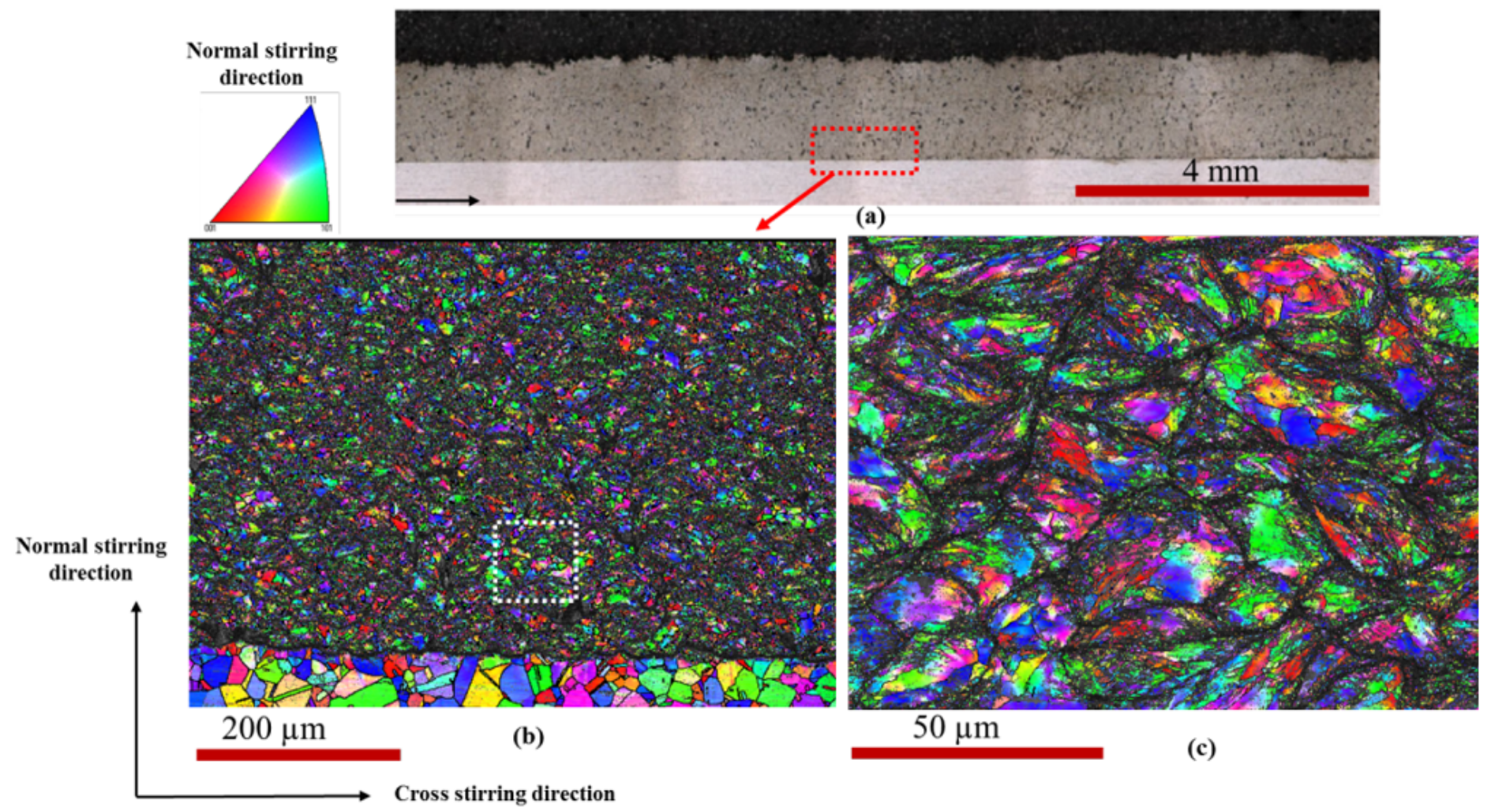

\section{Figure 13}

EBSD maps of as-sprayed stainless-steel Diamalloy 1003 coating on 304L substrate in Cross Stirring Direction - Normal Stirring Direction plane: (a) overview, (b) global view of the grain orientation map, and 
(c) local EBSD map in the coating corresponding approximately to the white dashed region in (b).

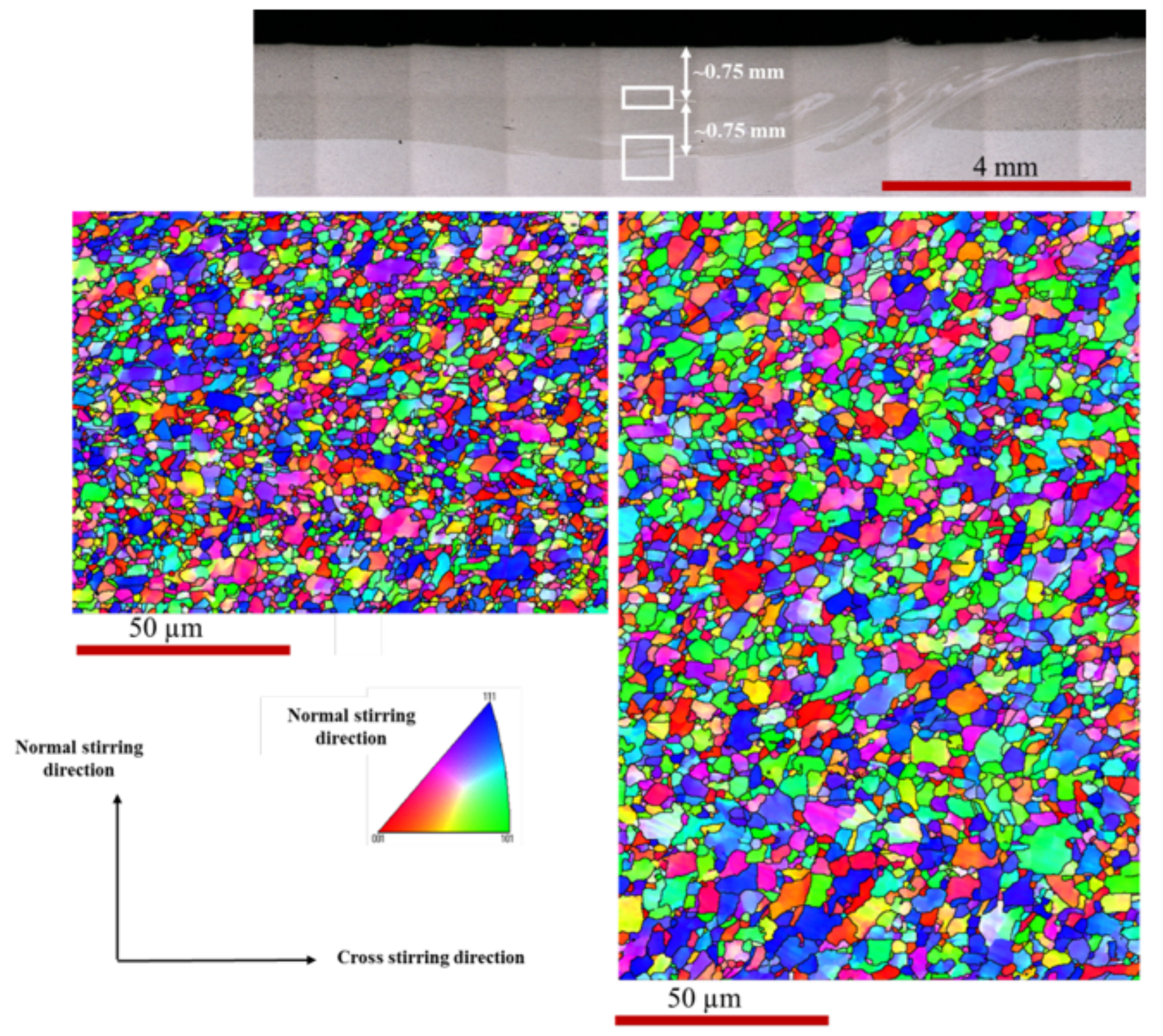

Figure 14

EBSD maps into the normal stirring direction in the middle of the treated zone at different depths inside the coating: $0.75 \mathrm{~mm}$ and $1.5 \mathrm{~mm}$. 

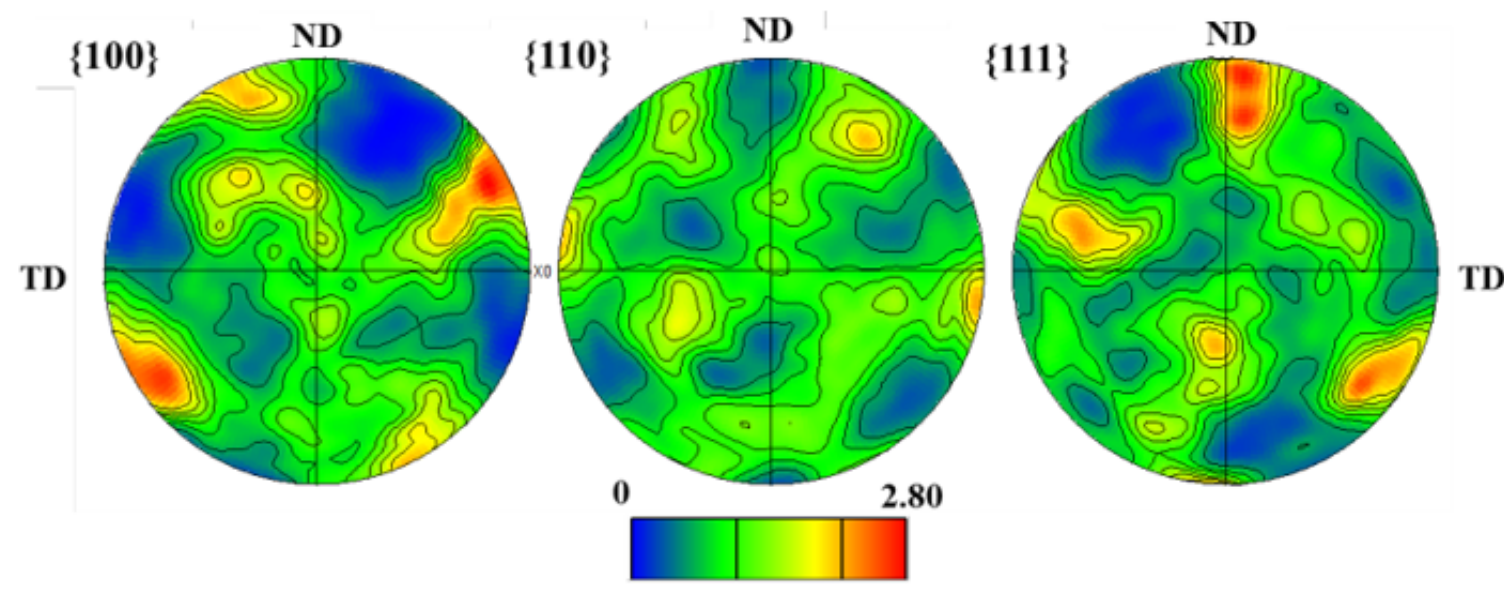

Normal stirring direction
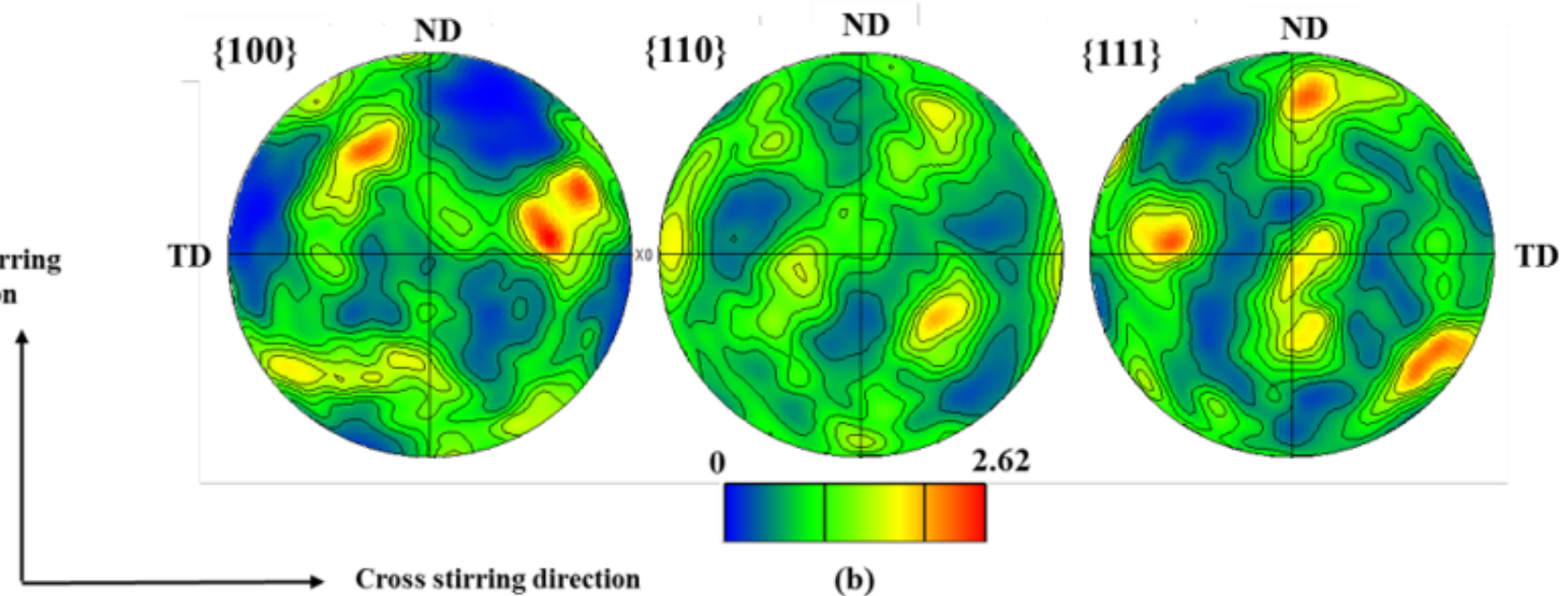

Cross stirring direction

(b)

\section{Figure 15}

$\{100\},\{110\}$ and $\{111\}$ contoured pole figures into the normal stirring direction in the middle of the treated zone at different depths inside the coating: (a) $0.75 \mathrm{~mm}$ and (b) $1.5 \mathrm{~mm}$ which correspond approximately to the half-thickness (top) and to the interface with the substrate (bottom). 


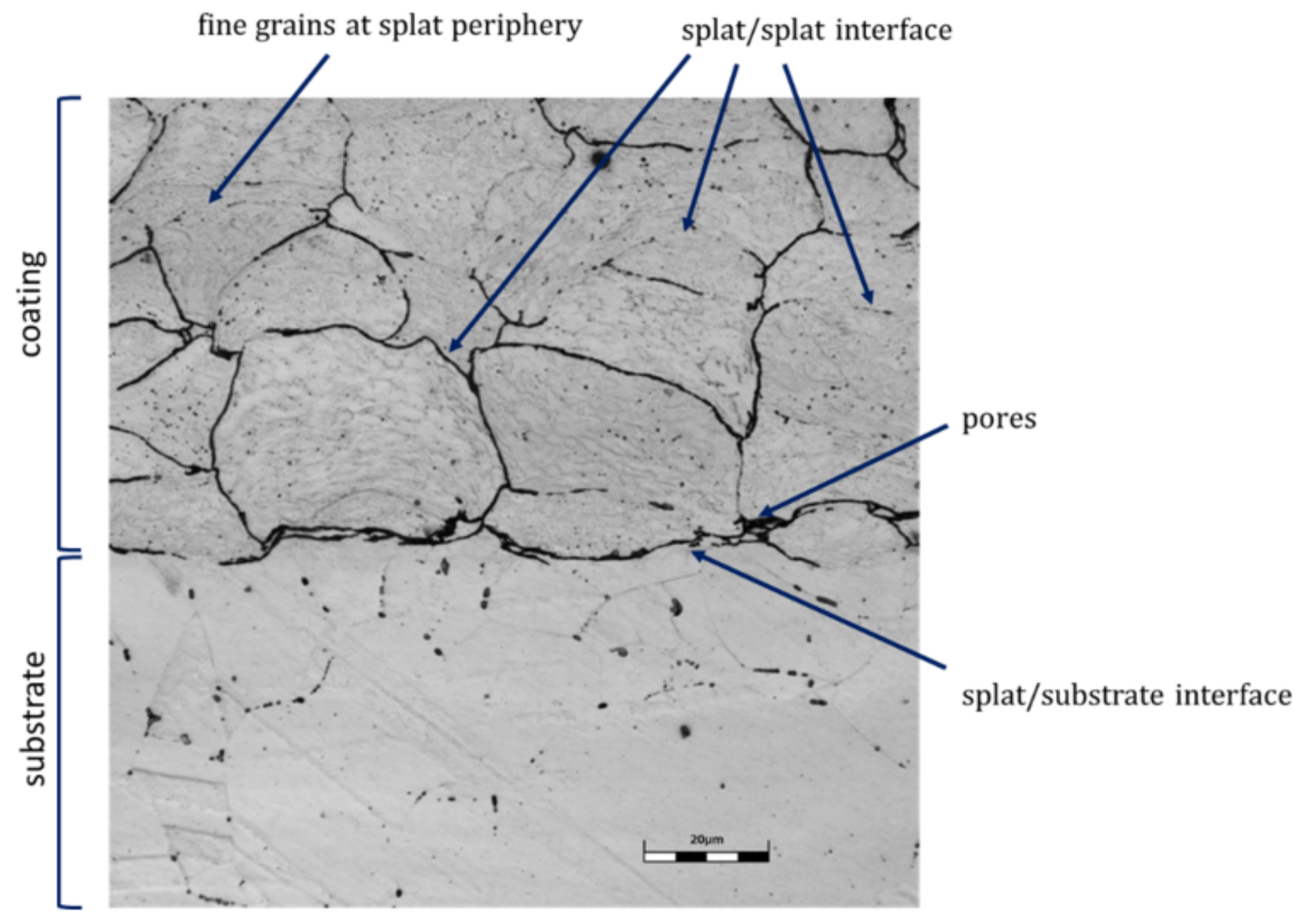

Figure 16

Structure of as-sprayed Diamalloy 1003 stainless steel coating on 304L substrate 


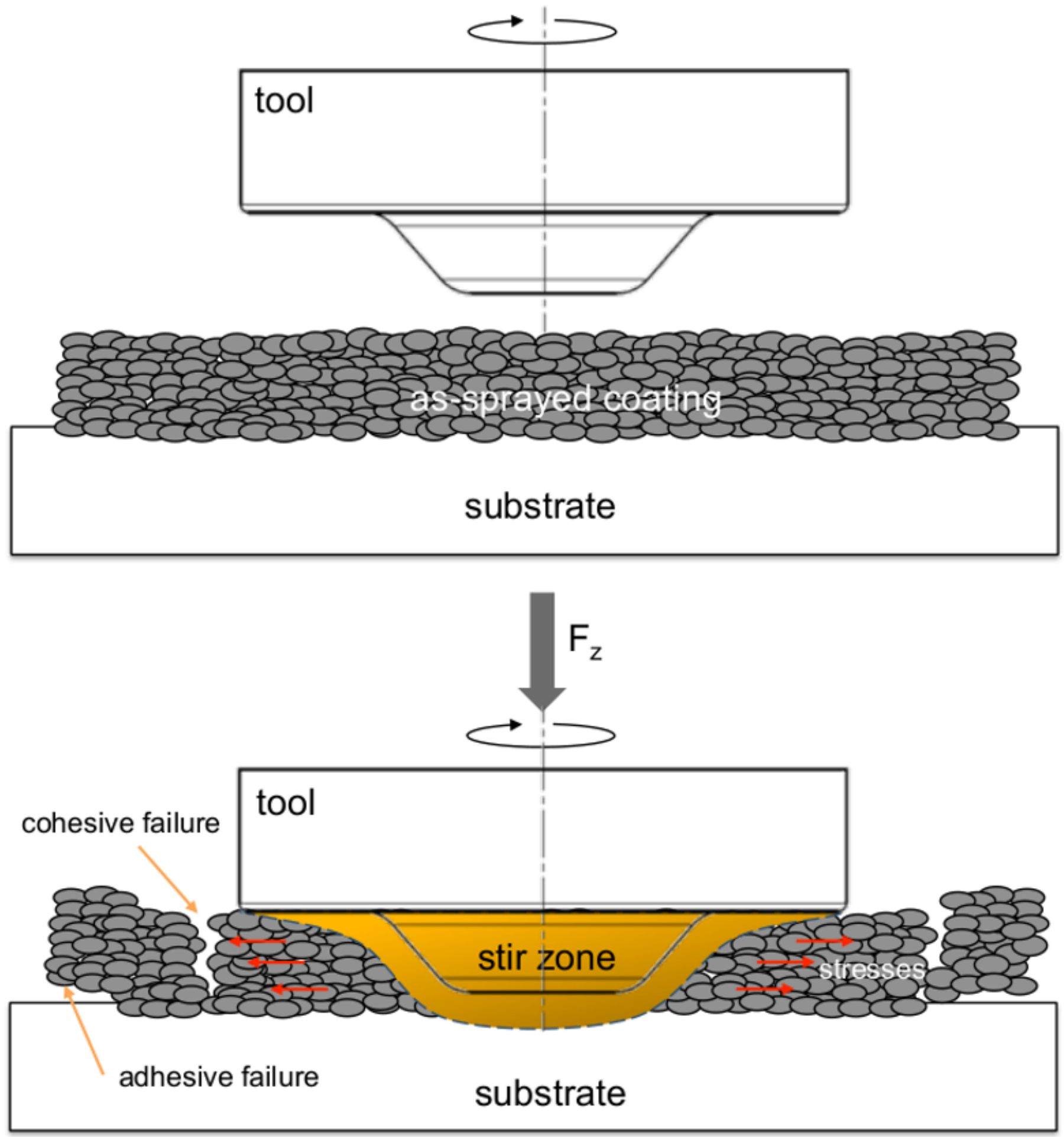

Figure 17

Schematics of coating failure during FSP process 


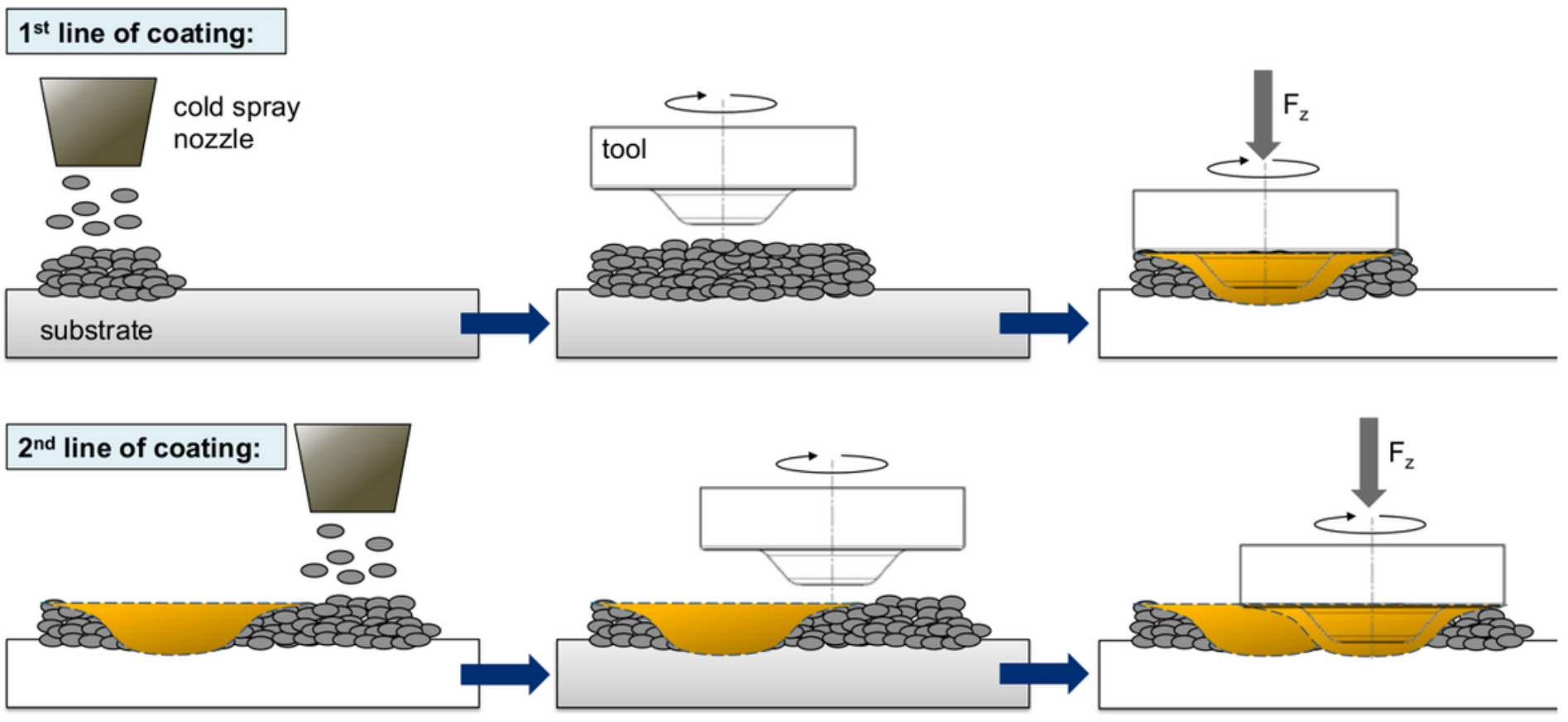

Figure 18

Consecutive deposition and further FSP treatment of the single lines of coating 